\title{
Neuropsychological Profile of Acute Alcohol Intoxication during Ascending and Descending Blood Alcohol Concentrations
}

\author{
Tom A Schweizer*,1, Muriel Vogel-Sprott ${ }^{2}$, James Danckert ${ }^{2}$, Eric A Roy ${ }^{2,3}$, Amanda Skakum ${ }^{3}$ and \\ Carole E Broderick ${ }^{2}$ \\ 'The Rotman Research Institute, Baycrest Centre for Geriatric Care, Toronto, ON, Canada; ${ }^{2}$ Department of Psychology, University of Waterloo, \\ Waterloo, ON, Canada; ${ }^{3}$ Department of Kinesiology, University of Waterloo, Waterloo, ON, Canada
}

\begin{abstract}
Numerous studies have investigated the effects of alcohol on motor processes during rising and declining blood alcohol concentrations (BAC), however, relatively little research has examined the alcohol-induced impairment of cognitive performance on the two limbs of the BAC curve. This experiment administered a neuropsychological test battery to assess the degree to which rising and declining BACs during an acute dose of alcohol impair nine cognitive processes within an individual. In all, 20 healthy male social drinkers (university students) were assigned to one of two groups $(n=10)$ who received a beverage containing either $0.0 \mathrm{~g} / \mathrm{kg}$ (placebo) or $0.65 \mathrm{~g} / \mathrm{kg}$ alcohol and performed the test battery when BAC was increasing and was decreasing. Comparisons of alcohol and placebo groups revealed impairment (slower response and/or increased errors) in seven of the cognitive processes: long-term verbal memory; information processing; declarative memory; inhibitory control; short-term visual memory; long-term visual memory, and visual-spatial working memory. However, some processes were impaired only during rising BACs whereas the impairment of others during declining BACs was evident only by an increase in errors. These results show cognitive tasks performed by an individual are not similarly affected by rising and declining BACs, and call attention to the importance of assessing both speed and accuracy on both limbs of the BAC curve. The particular cognitive processes differentially affected by rising vs declining BACs raised the possibility that acute alcohol intoxication may impair one cerebral hemisphere to a greater degree than the other, and this could be explored by neuroimaging techniques. Neuropsychopharmacology (2006) 3 I, I 30 I-1309. doi: I0.1038/sj.npp. I 30094 I; published online 26 October 2005
\end{abstract}

Keywords: alcohol; ethanol; cognition; neuropsychology; blood alcohol concentration curve

\section{INTRODUCTION}

Symptoms of intoxication from an acute dose of alcohol are characterized by impaired motor skills as well as cognitive abilities, such as deficits in impulse control, memory, and information processing. The consumption of alcohol typically results in blood alcohol levels that rise swiftly to a peak and then slowly decline. Numerous experiments with animals and humans during the last century have compared the effect of alcohol on motor performance during rising and declining limbs of the blood alcohol curve. These experiments have shown that the impairing effect of a given blood alcohol concentration (BAC) is greater on the rising

*Correspondence: Dr TA Schweizer, The Rotman Research Institute, Baycrest Centre for Geriatric Care, 3560 Bathurst Street, Toronto, ON, Canada M6A 2EI, Tel: +416785 2500 ext. 3439, Fax: +4I6 785 4295, E-mail: tschweizer@rotman-baycrest.on.ca

Received 16 May 2005; revised 7 September 2005; accepted 8 September 2005

Online publication: I4 September 2005 at http://www.acnp.org/ citations/Npp09|405050323/default.pdf than on the declining limb of the curve (eg LeBlanc et al, 1975; Mellanby, 1919; Vogel-Sprott and Fillmore, 1993). This reduction in impairment observed during declining BACs suggests some process of adaptation or habituation may occur during physiological exposure to a dose of alcohol (Kalant et al, 1971).

Compared to the extensive investigation of the impairment of motor processes on the two limbs of the BAC curve, relatively little research has examined alcohol-induced impairment of cognitive processes during rising and declining BACs. A test of the effects of alcohol on cognition during rising and declining $\mathrm{BAC}$ requires relatively short tests, and alternate forms to minimize practice effects. These requirements limit the use of most traditional clinical neuropsychological tests of cognitive function owing to their comparatively long administration time and potential practice effects when tests are repeated. Research in cognition has developed relatively brief computerized tasks to assess specific cognitive processes. These laboratory tasks are suitable for repeatedly testing the effects of an acute dose of alcohol at intervals around the BAC curve, and 
several have been used for this purpose. The results have usually confirmed the occurrence of impairment during rising BACs, but often find that impairment during declining BACs fail to show the customary reduction observed in motor skill performance. For example, inhibitory control of behavior under an acute dose of alcohol, assessed by a Go-Stop paradigm (Logan, 1994), has shown a fairly constant degree of impairment on tests during rising and declining BACs in the $50-80 \mathrm{mg} / \mathrm{dl}$ range (Fillmore and Vogel-Sprott, 1999; Mulvihill et al, 1997). Studies in which a drinker performs a motor skill and an informationprocessing task at the same BAC has found drinkers display impairment on both tasks during rising BACs, but only motor skill shows the customary reduction in impairment during declining BACs (Fogarty and Vogel-Sprott, 2002). Some research also suggests that the display of speed and accuracy on a given cognitive task may have different profiles of impairment under an acute dose of alcohol. Schweizer et al (2004) found information processing by social drinkers was slower and less accurate while BAC rose, but errors remained when BAC began to decline even though the speed of information processing had returned to drug-free levels. Although research on the effects of rising and declining BACs based on a single cognitive task is valuable, it cannot reveal the degree to which various cognitive processes within a given individual are affected during the course of an acute dose of alcohol.

Some computerized test batteries modeled on clinical neuropsychological tests have been developed that allow the assessment of numerous cognitive functions within an individual, but they have rarely been investigated in relation to rising and declining BACs. One exception is research that used multiple versions of two brief computerized neuropsychological tasks to assess cognitive executive functioning during rising and declining BACs (Pihl et al, 2003). These investigators tested performance at a BAC of $80 \mathrm{mg} / \mathrm{dl}$ in different groups of social drinkers during either rising or declining BACs. The results suggested that some cognitive processes entailed in executive functioning might actually be more intensely impaired during declining than rising BACs. Although these findings are potentially important, no drug-free baseline test was administered to show that the groups did not differ before treatment, and testing different groups on each limb of the curve could not control for possible individual differences in the sensitivity to alcohol. Clearer evidence would be obtained using a within-subject experimental design that administers baseline, ascending and descending BAC tests to a group that receives alcohol and one that receives a placebo.

Effects of rising and declining BACs on executive functioning involve cognitive processes associated with neural systems within the prefrontal cortex (Baddeley and Della Sala, 1998; Stuss and Alexander, 2000). However, it is possible that rising and declining BACs affect a wider range of cognitive processes associated with other brain areas. In addition to specific neuropsychological tests of executive function, computerized test batteries have been developed to assess cognitive functions as a result of brain injury, exposure to toxic substances and concussion. Concussions may affect one or both hemispheres, and cause focal (ie frontal or temporal lobe) or diffuse damage. Some investigators have noted that the symptoms of concussion bear a resemblance to the effects of psychoactive drugs, such as alcohol (Maruff et al, 2001). One computerized test battery used to assess concussion is ImPACT (Immediate Postconcussion Assessment and Cognitive Testing www. impacttest.com). The tests in ImPACT are modeled on well-known clinical and experimental neuropsychological tests that assess short and long-term visual and verbal memory, inhibitory control, visual-spatial working memory, declarative (explicit) memory, information processing, and immediate working memory. The brief tasks in the ImPACT battery can be administered during rising and declining limbs of the BAC curve, and practice effects are minimized by alternate forms of the tasks created by random variation of task stimuli (Collie and Maruff, 2003).

The present within-subject experiment uses a neuropsychological test battery to assess the degree to which rising and declining BACs during an acute dose of alcohol affect a gamut of cognitive processes within an individual. Given that the effect of alcohol on motor skills is more disrupting while BACs are rising than declining, it was predicted that cognitive performance on the neuropsychological tasks would show impairment during rising BACs (slower and/or less accurate responding). Our hypothesis was tested by planned comparisons of alcohol and placebo control groups on tests of the tasks during rising BACs. Alcohol effects during the declining phase of the BAC curve were explored by group comparisons.

\section{METHODS}

\section{Participants}

In all, 20 healthy male social drinkers (mean age 21.8 years, $\mathrm{SD}=2.2$ ) participated in the study. They were randomly selected from a large pool of university student volunteers for psychology experiments and were randomly assigned to an alcohol (A) group or a placebo (P) group of equal size $(n=10)$. All participants reported normal hearing and vision. They were taking no medication and agreed to fast for $4 \mathrm{~h}$ and abstain from alcohol $24 \mathrm{~h}$ prior to the test session. All participants were asked to refrain from using nicotine, caffeine, and any other over the counter medications prior to the test session. Ethical approval for the project was obtained from the University Office of Research Ethics and all volunteers provided informed consent prior to participating in the study.

\section{Apparatus and Materials}

Neuropsychological test battery (ImPACT). This test battery is completed in approximately 20-min and contains tasks that are briefly described below. Table 1 shows the name of each ImPACT task, the associated cognitive processes each purportedly measures and the accompanying dependent variables.

Word discrimination. Participants receive two practice sessions to learn 12 target words that are presented for $750 \mathrm{~ms}$ on a computer screen. Short-term verbal memory is immediately tested by presenting 24 words one at a time (ie 12 target words and 12 nontarget words semantically related to the targets). Participants are required to discriminate 
Table I ImPACT Neuropsychological Test Battery and the Corresponding Cognitive Processes and Measures of Performance

\begin{tabular}{|c|c|c|}
\hline ImPACT tests & Cognitive processes & Measures \\
\hline Immediate word discrimination & Short-term verbal memory & \% Correct \\
\hline Delayed word discrimination & Long-term verbal memory & \% Correct \\
\hline Immediate design memory & Short-term visual memory & $\%$ Correct \\
\hline Delayed design memory & Long-term visual memory & $\%$ Correct \\
\hline$X^{\prime}$ 's and $O^{\prime}$ 's & Visual-spatial working memory & $\%$ Correct \\
\hline Symbol match with key & Information processing & $\%$ Correct; RT \\
\hline Symbol match without key & Declarative (explicit) memory & \% Correct; RT \\
\hline Color match & Inhibitory Control & $\begin{array}{l}\text { \% Correct responses and RT for correct } \\
\text { responses; \% errors of commission and RT for } \\
\text { errors of commission }\end{array}$ \\
\hline Three letters & Immediate working memory & $\%$ Correct \\
\hline
\end{tabular}

targets from nontarget words by clicking 'yes' or 'no' buttons on the computer screen. Long-term verbal memory is also tested by administering the same 24 words approximately $20 \mathrm{~min}$ later. The percent correct responses are recorded on the immediate and the delayed task.

Design memory. In all, 12 abstract line designs are displayed on a computer monitor for $750 \mathrm{~ms}$ and the sequence is presented twice to familiarize participants with the designs. Short-term visual memory is immediately tested by presenting 24 designs, consisting of the 12 target designs and 12 nontarget designs. Designs are presented individually and participants are required to discriminate target from nontarget designs by clicking 'yes' or 'no' buttons on the screen. Long-term visual memory is tested by administering the same 24 designs approximately 20 -min later. The percent correct responses are recorded on the immediate and the delayed task.

$X$ 's and O's. This task assesses visual-spatial working memory. On each trial, a computer-generated random matrix of X's and O's is presented on the monitor for $1.5 \mathrm{~s}$. The matrix contains three randomly selected X's or O's that are highlighted in yellow. Participants are asked to remember their location while they perform a secondary task (ie left or right click on a mouse to the presentation of a blue square or red circle on the monitor). The secondary task is performed for 30-s and is immediately followed by the $\mathrm{X}-\mathrm{O}$ matrix with no highlighting. The previously highlighted X's or O's are to be identified via a mouse click, and the participant is allowed to revise the selections until satisfied that they are correct. A test on the task consists of four trials. The percentage of highlighted X's or O's that were correctly identified on a test is recorded.

Symbol matching. Participants are presented with a reference key that associates nine abstract symbols with numbers 1-9. A symbol is presented below this grid and the participant must click the associated number as quickly as possible. Feedback on correct responses is provided by the illumination of the number. A test with the reference key consists of a total of 27 trials and assesses information processing. This test is followed by another 27-trial test that presents the numbers but removes the reference key.
Symbols are presented one at a time and participants are required to click the number that had been associated with the symbol. Thus, participants must remember the previous symbol-number associations in order to recall the appropriate symbol. This no-key task assesses declarative (explicit) memory, which is described as the ability to consciously recall previously learned information (Lezak, 1995). Response Time (RT) and correct responses are recorded for the key and no-key test.

Color match. A color word (eg RED) is presented on the monitor in either the same colored ink as the word, or in different colored ink (eg green or blue). Participants are instructed to click on the image as quickly as possible only if the word is presented in matching ink (eg RED printed in the color red). A test presents 27 color words. Nine (33\%) provide a color word in matching ink and require a response. Percent correct responses to these nine items are recorded as well as the RT of correct responses. The remaining 18 words require inhibition. Errors of commission (ie failures to inhibit responses to mismatched color items) and the RT of errors are recorded.

Three letters. This task measures immediate working memory. The computer monitor presents a randomly selected set of three consonants that must be held in working memory for 18-s before participants type the consonants into the computer. To ensure that the consonants are not rehearsed during the 18-s interval, participants are required to engage in a backward counting task (ie clicking on a grid of scrambled numbers 1-25, in backwards order). A test consists of five trials, and the total percentage of correctly identified consonants is recorded.

Personal drinking habits questionnaire. This questionnaire (Vogel-Sprott, 1992) yields three measures of a drinker's current drinking habits: frequency (typical number of drinking occasions per week); typical dose ( $\mathrm{ml}$ alcohol $/ \mathrm{kg}$ ) per occasion; and duration (time span in hours of a typical drinking occasion). Two additional questionnaire items asked participants if they had ever been convicted for impaired driving and if they had ever experienced any problems due to their drinking. These questions were used to screen out anyone with potential 
alcohol problems. No participant, however, reported any alcohol problems.

Beverage rating. All participants completed a beverage rating scale (eg Fillmore and Vogel-Sprott, 2000) to report the perceived alcoholic content of their beverages in terms of 344-ml bottles of beer containing $5 \%$ alcohol. The scale ranged from $0-10$ bottles of beer, in 0.5 bottle increments. The scale was used to assess the credibility of the placebo by determining whether those who received the placebo reported that their beverage contained alcohol.

\section{Procedure}

Test sessions were conducted between the hours of 1100 and 1500. Prior to commencing the computerized tests each participant read the task instructions provided to them on the computer screen. The research assistant then reiterated the task requirements and answered any questions regarding the specific tasks. The ImPACT test battery was then administered in order to provide baseline measures of performance prior to any treatment.

After baseline testing, participants in the A group were given $0.65 \mathrm{~g}$ of ethanol per kilogram of body weight. The dose of alcohol was divided into two drinks containing two parts carbonated fruit-flavored soda and one part alcohol. Participants in the $\mathrm{P}$ group received an equivalent per $\mathrm{kg}$ volume of the soda, served in two glasses with $5 \mathrm{ml}$ of ethanol floated on the surface of the beverage. To encourage the perception that they were drinking an alcoholic beverage the glasses were sprayed with a 50/50 ethanolwater mixture. The two drinks were served $5 \mathrm{~min}$ apart and participants consumed each drink within $1 \mathrm{~min}$. After consuming both drinks, participants rinsed their mouths with water to remove any residual mouth alcohol. They then rested in the laboratory room and read magazines until their tests commenced.

The alcohol-dosing regimen aimed to produce a peak BAC of $100 \mathrm{mg} / \mathrm{dl}$ approximately $70-90 \mathrm{~min}$ postdrug ingestion. Testing on ImPACT began at 35 and at $95 \mathrm{~min}$ after drinking commenced. The two tests were scheduled so that those who received alcohol would have ascending BACs during the test that commenced at $35 \mathrm{~min}$. The test beginning at $95 \mathrm{~min}$ ensured that it occurred during the descending phase of the blood alcohol curve. BACs were obtained at 32,60,82, 92, and 120 min after drinking started and were measured from breath samples by an Intoxilyzer, Model S-D2 (CMI Inc., Owensboro, KY). Participants who received the placebo also provided breath samples at those times, ostensibly to measure their BAC. The session concluded at $120 \mathrm{~min}$ postdrinking. Participants then completed the beverage rating scale, received a snack and remained at leisure in the laboratory until their BAC fell to $30 \mathrm{mg} / 100 \mathrm{ml}$. At this time, they were paid and debriefed.

\section{Data Analyses}

Each measure of performance on a task was analyzed separately by an overall 2 Group (placebo, alcohol) $\times 3$ Test (baseline, ascending, descending) Analysis of Variance (ANOVA). Planned group comparisons tested the prediction that the A group would be impaired on the test during ascending BACs and between group comparisons served to explore alcohol effects during descending BACs.

\section{RESULTS}

\section{Procedural Checks}

Independent $t$-tests comparing groups on each drinking habit measure obtained no significant group differences $(p$ 's $>0.70)$. The sample $(N=20)$ reported a mean weekly drinking frequency of $1.98(\mathrm{SD}=1.23)$. The mean duration of a drinking occasion was $4.00 \mathrm{~h}(\mathrm{SD}=1.30)$ and the mean dose per occasion was $1.13 \mathrm{ml} / \mathrm{kg}(\mathrm{SD}=0.44)$. For a $75 \mathrm{-kg}$ person, the mean dose and duration of drinking approximates the consumption of 2.4 bottles ( $344 \mathrm{ml}$ ) of $5 \%$ alcohol beer over a 2-h period. The National Institute on Alcohol Abuse and Alcoholism (NIAAA) National Advisory Council has defined binge drinking as the consumption of five or more drinks within $2 \mathrm{~h}$ for men, as this rate of consumption is estimated to result in a BAC of at least $80 \mathrm{mg} / 100 \mathrm{ml}$ (NIAAA, 2004).

Participants in the $\mathrm{P}$ group had no detectable BACs. At $32 \mathrm{~min}$ after drinking began (ie just prior to the first treatment test) the mean $\mathrm{BAC}$ of those in the A group was $81 \mathrm{mg} / \mathrm{dl} \quad(\mathrm{SD}=33 \mathrm{mg} / \mathrm{dl})$. When the test concluded at $60 \mathrm{~min}, \mathrm{BAC}$ had risen to $93 \mathrm{mg} / \mathrm{dl}(\mathrm{SD}=21 \mathrm{mg} / \mathrm{dl})$. A mean peak BAC of $96 \mathrm{mg} / \mathrm{dl}(\mathrm{SD}=25 \mathrm{mg} / \mathrm{dl})$ occurred at $82 \mathrm{~min}$. At $92 \mathrm{~min} B A C$ had fallen to $86 \mathrm{mg} / \mathrm{dl}(\mathrm{SD}=18 \mathrm{mg} / \mathrm{dl})$, and it had declined further, to $79 \mathrm{mg} / \mathrm{dl}(\mathrm{SD}=16 \mathrm{mg} / \mathrm{dl})$ at $120 \mathrm{~min}$ postdrinking.

No participant who received a placebo rated the alcohol in his drinks as zero. Thus, the placebo appeared to be credible. The mean rating in the $\mathrm{P}$ group was equivalent to $1.86(\mathrm{SD}=1.35)$ bottles of $5 \%$ beer and for the A group it was equivalent to $4.84(\mathrm{SD}=1.4)$.

Comparisons of the A and $\mathrm{P}$ groups on the baseline test of each task obtained no significant effects ( $p$ 's $>0.18$ ). These results showed that the performance of the two groups did not differ prior to any treatment. Thus, because prime interest attaches to the differences between alcohol and placebo groups during the ascending and descending limb of the BAC curve, group comparisons are only reported for these two treatment tests.

\section{Treatment Effects}

Group mean scores on the three tests of all tasks are presented in Table 2.

Short-term verbal memory. A 2 Group (placebo, alcohol) $\times 3$ Test (baseline, ascending, descending) ANOVA of \% correct responses on Immediate Word Discrimination revealed a significant main effect of Test $\left(\mathrm{F}_{2,36}=3.54\right.$, $p=0.04)$. The groups did not differ on tests during ascending or descending BACs ( $p$ 's $>0.10)$. The main effect of test arose because the combined groups $(N=20)$ were most accurate on the baseline test (99\% correct responses) and displayed $97 \%$ correct responses on each of the treatment tests.

Long-term verbal memory. A 2 Group $\times 3$ Test ANOVA of $\%$ correct responses on Delayed Word Discrimination 
Table 2 Mean (SD) Performance Measures of Processes Assessed by the Computerized Neuropsychological Tasks for a Group Receiving Alcohol and a Placebo Control

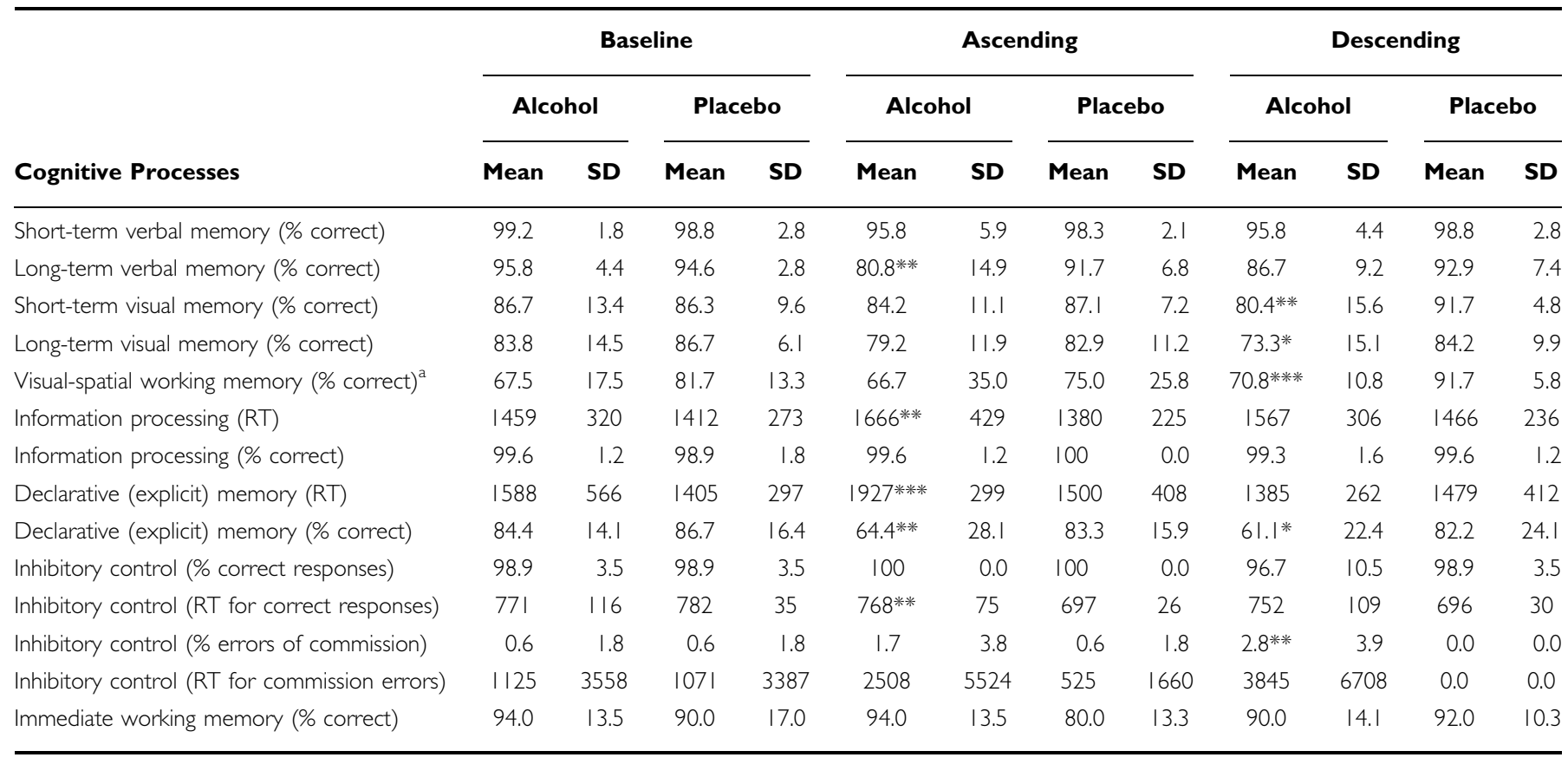

All reported $\mathrm{RT}$ s are in milliseconds.

${ }^{\mathrm{a}}$ Group $\mathrm{A} n=7 ; \mathrm{P} n=5$.

**** $p=<0.01$; *** $p=<0.05$; $p=<0.08$.

revealed a Group $\times$ Test interaction $\left(\mathrm{F}_{2,36}=4.09, p=0.025\right)$. Group means on each test are plotted in Figure 1a. The A group was significantly less accurate than the $\mathrm{P}$ group during the ascending test $\left(t_{18}=2.098, p=0.025\right)$, and the groups did not differ on the descending test $(p=0.11)$.

Short-term visual memory. A 2 Group $\times 3$ Test ANOVA of $\%$ correct responses on Immediate Design Memory revealed a significant Group $\times$ Test interaction $\left(\mathrm{F}_{2,36}=4.23\right.$, $p=0.022)$. Group means on each test are plotted in Figure 1b. Planned comparisons showed that the groups did not differ on the test during ascending BACs $(p=0.50)$. However, the A group was less accurate than the P group on the test during descending BACs $\left(t_{18}=2.18, p=0.043\right)$.

Long-term visual memory. A 2 Group $\times 3$ Test ANOVA of $\%$ correct responses on Delayed Design Memory revealed a main effect of Test $\left(\mathrm{F}_{2,36}=3.31, p=0.048\right)$. The mean $\%$ correct responses tended to decline progressively over the three tests, from $85 \%$ on the baseline test, to $81 \%$ on the ascending test, and $79 \%$ on the descending test. Planned comparisons detected no significant group differences on the ascending BAC test $(p=0.479)$. The A group was less accurate than the $\mathrm{P}$ group on the descending test, but this difference was only marginally significant $(p=0.08)$.

Visual-spatial working memory. Computer malfunction caused the loss of measures of correct responses for three participants in the A group and five in the $\mathrm{P}$ group. Independent $t$-tests of the \% correct responses of the groups on each test showed no significant group differences during ascending $\mathrm{BAC}(p$ 's $>0.18)$. However, the A group was
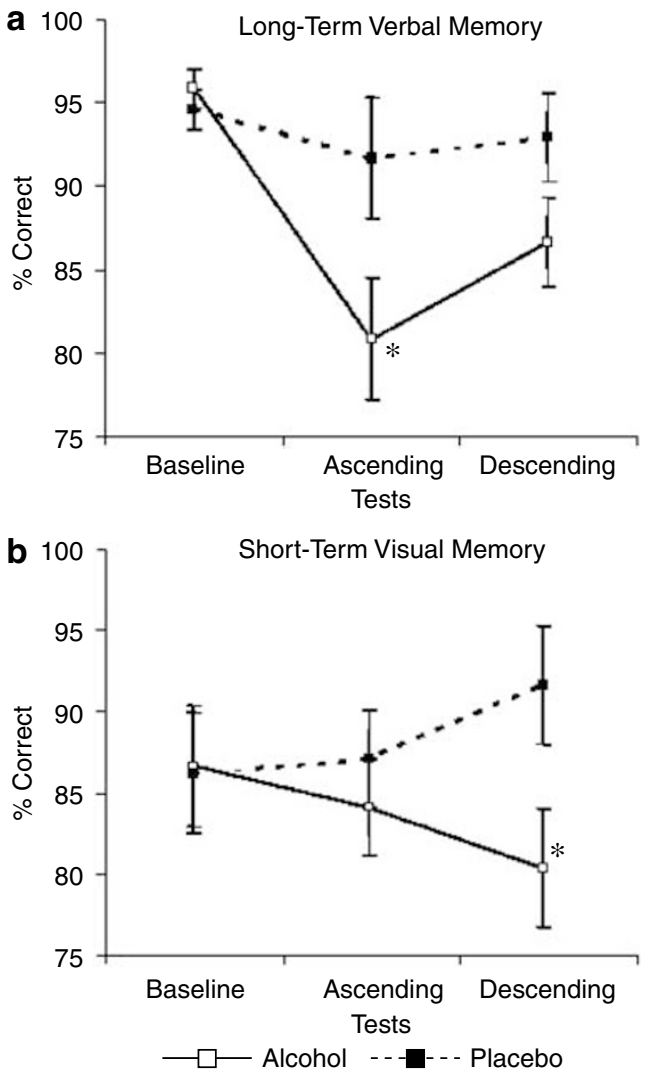

Figure I Mean \% correct responses on long-term verbal memory (a) and short-term visual memory (b) by alcohol and placebo groups during baseline, ascending and descending tests. (vertical bars show SEMs; * indicates significant group differences). 

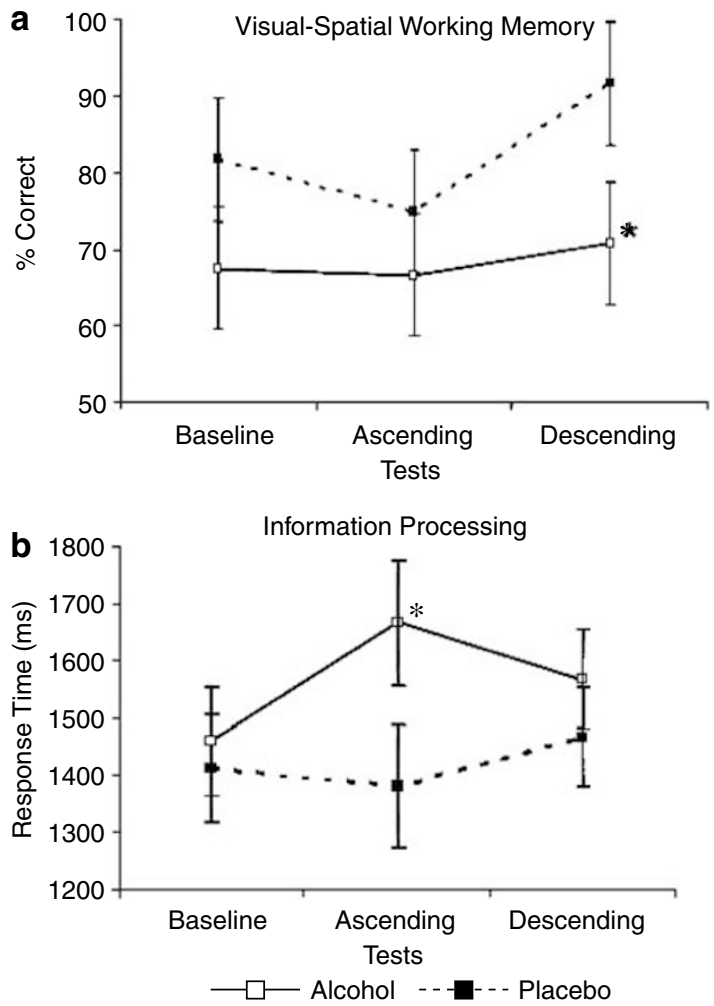

Figure 2 Mean \% correct responses on visual-spatial working memory (a) and mean response time on information processing (b) by alcohol and placebo groups during baseline, ascending and descending tests (vertical bars show SEMs; * indicates significant group differences).

significantly less accurate during declining BACs $\left(t_{7}=3.73\right.$, $p<0.007$ ), and displayed a mean of $71 \%$ correct responses as compared with a mean of $92 \%$ in the $P$ group. The group means on each test are plotted in Figure 2a.

Information processing. A 2 Group $\times 3$ Test ANOVA of RT on Symbol matching with a reference key yielded a significant Group $\times$ Test interaction $\left(\mathrm{F}_{2,36}=3.44, p=0.043\right)$. Figure $2 \mathrm{~b}$ illustrates the interaction. Planned comparisons showed that the RT of the A group during ascending BACs was significantly slower than the P group $\left(t_{18}=1.87\right.$, $p<0.039$ ), and they did not differ during descending BACs $(p>0.42)$.

A 2 Group $\times 3$ Test ANOVA of \% correct responses obtained no significant effects $(p$ 's $>0.29)$ and group comparisons also detected no differences on ascending or descending BAC tests $(p$ 's $>0.34)$. Accuracy in both groups was very high, and the sample $(N=20)$ mean $\%$ correct responses per test was $99.5(\mathrm{SD}=0.006)$.

Declarative (explicit) memory. A 2 Group $\times 3$ Test ANOVA of the RT when Symbol Matching was performed with no reference key obtained a main effect of Test $\left(\mathrm{F}_{2,36}=3.26\right.$, $p=0.05)$ and a marginally significant Group $\times$ Test interaction $\left(\mathrm{F}_{2,36}=2.54, p=0.09\right)$. The group mean $\mathrm{RT}$ on each test, presented in Figure 3a, shows the RT of the A group was slower than the $\mathrm{P}$ group on the test during ascending BACs, $\left(t_{18}=2.67, p<0.008\right)$. Group differences were not significant on the descending BAC test $(p>0.55)$.
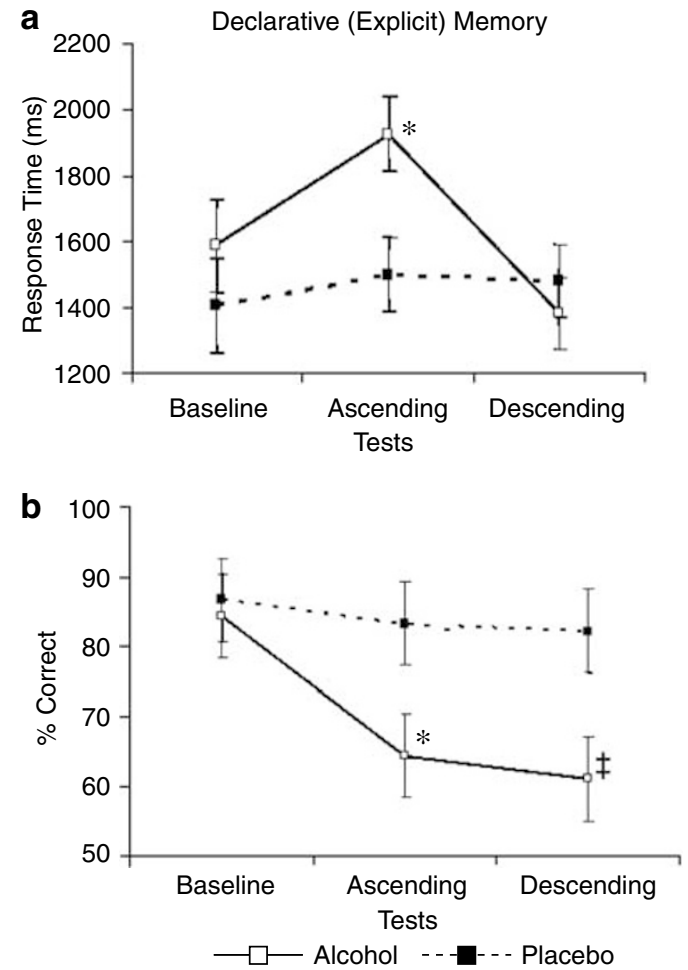

Figure 3 Mean response time (a) and mean \% correct responses (b) on declarative (explicit) memory by alcohol and placebo groups during baseline, ascending and descending tests (vertical bars show SEMs; * indicates significant group differences and $\ddagger$ indicates $p=0.057$ ).

The 2 Group $\times 3$ Test ANOVA of $\%$ correct responses obtained main effects of Group $\left(\mathrm{F}_{1,18}=4.73, p=0.043\right)$ and Test $\left(\mathrm{F}_{2,36}=3.34, p=0.047\right)$. Group means on each test are plotted in Figure $3 \mathrm{~b}$. As predicted, the A group during ascending BACs displayed fewer correct responses than the $\mathrm{P}$ group $\left(t_{18}=1.85, p<0.04\right)$. The A group was also less accurate during descending BACs, but group differences only approached significance $(p=0.057)$.

Inhibitory control. Both groups responded correctly to $99.9 \%$ of the nine images presenting a color word in matching ink. In contrast, the 2 Group $\times 3$ Test ANOVA of the RT of these correct responses obtained a main effect of Test $\left(\mathrm{F}_{2,36}=5.22, p=0.01\right)$ as well as a Test $\times$ Group interaction that approached significance $\left(\mathrm{F}_{2,36}=3.13\right.$, $p=0.056$ ). The mean RT of the A and $\mathrm{P}$ groups on each test is presented in Figure 4a. Planned comparisons showed that the A group responded more slowly while BACs were ascending $\left(t_{18}=2.02, p<0.03\right)$. The A group also responded more slowly during descending BACs, although this difference was not significant $(p>0.23)$.

Commission errors represented failures to inhibit responses to mismatched color words and ink. An ANOVA of errors was not justified because the $\mathrm{P}$ group displayed no errors on the descending BAC test. Thus, a $\chi^{2}$ analysis of the errors using the Fisher exact test for a $2 \times 2$ table was applied (Fisher, 1954). Analyses of the number of errors in each group on each test showed the A group displayed more errors than the $\mathrm{P}$ group while $\mathrm{BAC}$ was descending $(p<0.03)$. The errors in the groups did not differ during 

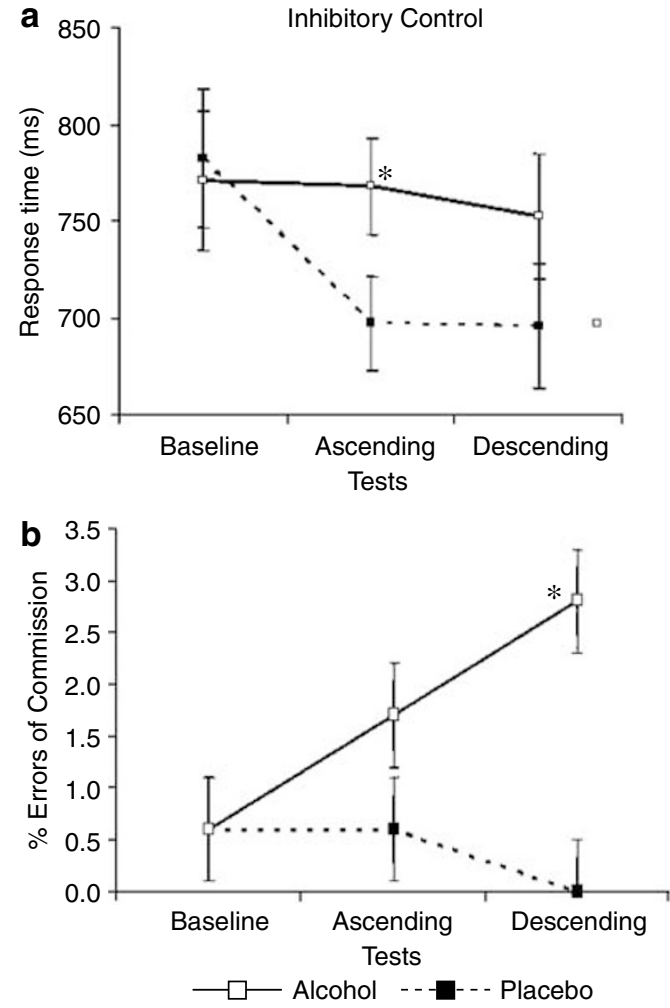

Figure 4 Mean response time for correct responses (a) and mean \% errors of commission (b) on inhibitory control by alcohol and placebo groups during baseline, ascending and descending tests (vertical bars show SEMs; * indicates significant group differences).

ascending BACs ( $p$ 's $>0.26)$. Group mean \% commission errors on each test are shown in Figure $4 \mathrm{~b}$.

The RT of commission errors could only be recorded for those who failed to inhibit their response, and no RT was obtained from the $\mathrm{P}$ group on the descending test. The RT of groups while BAC was ascending did not differ significantly ( $p$ 's $>0.29)$.

Immediate working memory. A 2 Group $\times 3$ Test ANOVA of the percentage of correct three letter responses obtained no significant effects ( $p$ 's $>0.13$ ). Comparisons of the A and $P$ groups detected no significant impairment in the A group on tests during ascending and descending BACs. The combined groups displayed $87 \%$ correct responses on the ascending $\mathrm{BAC}$ test and $91 \%$ on the descending BAC test.

\section{DISCUSSION}

The present within-subject experiment administered a neuropsychological concussion test battery to assess the impairing effect of an acute dose of alcohol on nine different cognitive processes during rising and declining BACs. Comparisons of alcohol and placebo groups revealed impairment (slower response and/or increased errors) in seven of the nine processes. Table 2 shows the hypothesis that rising BACs impair cognitive performance was confirmed for four cognitive processes (long-term verbal memory, information processing, declarative memory and inhibitory control), and three other processes were impaired only on tests during declining BACs (short-term visual memory, long-term visual memory and visual-spatial working memory). The two remaining processes (shortterm verbal memory and immediate working memory) revealed no significant effects of alcohol. The effect of alcohol on these processes may have been more subtle than the concussion symptoms which the tasks were designed to detect. In addition, the test of immediate working memory presented only three items. This is considerably fewer items than the maximum number that can be held on-line by healthy young adults (Kane and Engle, 2002), and research indicates that alcohol only begins to impair working memory when the number of items is near capacity (Grattan-Miscio and Vogel-Sprott, 2005). None-the-less, the effects of alcohol on these cognitive processes clearly show that different cognitive tasks performed by a given individual are not affected similarly by rising or by declining BACs.

Alcohol-induced impairment of most processes was revealed by a decrement in performance from baseline as compared to no change under the placebo. However, tests of two processes, illustrated in Figures 2a and 4a, appeared to involve some learning because the performance of the Placebo group improved from baseline whereas the performance of the Alcohol group remained relatively constant. The potential confounding effect of practice on these two processes clouds the interpretation of the impairment shown in the Alcohol group. For example, the benefit of practice might be prevented by alcohol, or practice under alcohol might counteract the drug-induced decrement in performance. Recent research suggests that practice under alcohol may counteract the impairing effects of the drug on an information-processing task (Schweizer et al, 2005). While this may be the case for some cognitive processes, different cognitive tasks may not be similarly affected.

Even though the neuropsychological battery did not provide measures of RT and errors for all tasks, the results suggested an interesting difference between the two measures in their sensitivity to the effects of declining BACs. Table 2 shows that impairment of cognitive processes during rising BACs was identified by $\mathrm{RT}$ and/or errors. In contrast, RT detected no impairment during declining BAC, but errors continued to reveal impairment. Other research has also found errors in cognitive performance may linger or increase during declining BACs even though RT has returned to drug-free levels (Schweizer et al, 2004). Although evidence for this phenomenon is accumulating, the underlying factors are poorly understood. One interesting possibility has been raised by the analysis of behavioral control under alcohol in terms of the basic processes of response activation and inhibition (Fillmore et al, in press). It may be that the failure of RT to detect impairment during declining BACs when it is evident in errors may be due to RT being primarily sensitive to activation whereas errors in withholding incorrect responses are more closely related to inhibitory processes. This possibility, as well as the fact that efficient cognitive performance requires both speed and accuracy, indicates that future research on the effect of alcohol on cognitive processes should measure both aspects of performance during rising and declining phases of the BAC curve. 
Another factor that might contribute to differences in impairment among cognitive tasks during rising and declining BACs is raised by some studies that suggest an acute dose of alcohol may impair one cerebral hemisphere to a greater degree than the other (Lamb and Robertson, 1987; Pihl et al, 2003). Inspection of our data (Table 2) shows that three cognitive processes (short- and long-term visual memory, and visual-spatial working memory) only revealed impairment during declining BACs, and these processes are putatively associated with right hemisphere processing (Carlesimo et al, 2001; Goldstein et al, 1988). One other process, long-term verbal memory, which is associated with left hemisphere functioning (Goldstein $e t$ al, 1988), was impaired only during rising BACs. Although these observations are necessarily speculative and require further testing, they suggest that each cerebral hemisphere may be differentially sensitive to rising and declining BACs.

Although mounting evidence indicates that cognitive processes are not similarly affected by rising and declining BACs, the associated underlying neural mechanisms remain unclear. One potentially useful approach to investigate the in vivo effects of acute alcohol intoxication on cognitive performance is neuroimaging. Although many studies have used fMRI and PET imaging techniques to elucidate the neural effects of chronic alcoholism, only a few have addressed the effects of an acute dose of alcohol on cognitive performance (eg Schreckenberger et al, 2004; Vogel-Sprott et al, 2001). These neuroimaging studies have only assessed cognition in a single domain, such as attention or inhibitory control. Schreckenberger et al (2004) may be the only investigators that aimed to test cognitive performance during rising and declining BACs, but their procedure of using intravenous alcohol resulted in such a rapid rise in BAC that tests could only be administered after peak BACs had occurred. Future neuroimaging research that administers a battery of computerized cognitive tasks, which are linked to a specific brain hemisphere, could explore possible differences between hemispheres in sensitivity to rising and declining BACs.

The results of this current research present new evidence to show that some cognitive processes within an individual are differentially affected by rising and declining BACs. This evidence was obtained from male social drinkers. Additional research would be required to determine if the findings on these cognitive processes also characterize female social drinkers and whether they generalize to more experienced drinkers or to those who drink heavily. The generality of the evidence from the present study also would have to be evaluated by examining the effect of alcohol on other types of cognitive processes in relation to the limb of the BAC curve. What is clear from the current evidence is that an adequate assessment of the effect of a dose of alcohol on cognitive processes must measure both speed and accuracy of performance on each limb of the curve. These behavioral results also set the stage for research using neuroimaging techniques to examine the relation of rising and declining $\mathrm{BAC}$ to brain areas when an individual performs different cognitive tasks.

\section{ACKNOWLEDGEMENTS}

This work was supported by a Natural Sciences and Engineering Research Council (NSERC) Doctoral Award to
TAS, an NSERC CRC and Discovery Grant to JD and a Canadian Institutes of Health Research Seed Grant to EAR and JD.

\section{REFERENCES}

Baddeley A, Della Sala S (1998). Working memory and executive control. In: Roberts A, Robbins T, Weiskrantz L (eds). The Prefrontal Cortex: Executive and Cognitive Functions. Oxford Press: New York. pp 9-21.

Carlesimo AC, Perri R, Turriziani P, Tomaiuolo F, Caltagirone C (2001). Remembering what but not where: Independence of spatial and visual working memory in the human brain. Cortex 36: 519-534.

Collie A, Maruff P (2003). Computerized neuropsychological testing. Br J Sports Med 37: 2-3.

Fillmore MT, Marczinski CA, Bowman AM (in press). Acute tolerance to alcohol effects on inhibitory and activational mechanisms of behavioral control. J Stud Alcohol.

Fillmore MT, Vogel-Sprott M (1999). An alcohol model of impaired inhibitory control and its treatment in humans. Exp Clin Psychopharmacol 7: 49-55.

Fillmore MT, Vogel-Sprott M (2000). Response inhibition under alcohol: effects of cognitive and motivational conflict. J Stud Alcohol 61: 239-246.

Fisher RA (1954). Statistical Methods for Research Workers, 12th edn. Revised. Oliver and Boyd: London, England. p 96.

Fogarty J, Vogel-Sprott M (2002). Cognitive processes and motor skills differ in sensitivity to impairment during a moderate dose of alcohol. J Stud Alcohol 63: 404-411.

Goldstein LH, Canavan AG, Polkey CE (1988). Verbal and abstract designs paired associate learning after unilateral temporal lobectomy. Cortex 24: 41-52.

Grattan-Miscio KE, Vogel-Sprott M (2005). Effects of alcohol and performance incentives on immediate working memory. Psychopharmacology 81: 188-196.

Kalant H, LeBlanc AE, Gibbins RJ (1971). Tolerance to, and dependence on, some non-opiate psychotropic drugs. Pharmacol Rev 23: 135-191.

Kane MJ, Engle RW (2002). The prefrontal cortex in workingmemory capacity, executive attention, and general fluid intelligence: An individual-differences perspective. Psychonom Bull Rev 9: 637-671.

Lamb MR, Robertson LC (1987). Effect of acute alcohol on attention and the processing of hierarchical patterns. Alcohol: Clin Exp Res 11: 243-248.

LeBlanc AE, Kalant H, Gibbins RJ (1975). Acute tolerance to ethanol in the rat. Psychopharmacology 41: 43-46.

Lezak MD (1995). Neuropsychological Assessment, 3rd edn. Oxford University Press: New York.

Logan DG (1994). On the ability to inhibit thought and action: A user's guide to the stop signal paradigm. In: Dagenbach D, Carr TH (eds). Inhibitory Processes in Attention, Memory and Language. Academic Press: San Diego California. pp 189-239.

Maruff P, Collie A, Darby D (2001). Quantifying the cognitive impairment associated with concussion: Using blood alcohol concentration as a reference point. Br J Sports Med 35: 373.

Mellanby E (1919). Alcohol: its absorption into and disappearance from the blood under different conditions. (Special Report Series Monograph No. 31) London, Medical Research Committee.

Mulvihill L, Skilling T, Vogel-Sprott M (1997). Alcohol and the ability to inhibit behavior of men and women. J Stud Alcohol 58: 600-605.

National Institute on Alcohol Abuse and Alcoholism (2004). NIAAA Council approves definition of binge drinking. NIAAA Newsletter No. 3, Winter. 
Pihl RO, Paylan SS, Gentes-Hawn A, Hoaken PNS (2003). Alcohol affects executive cognitive functioning differentially on the ascending versus descending limb of the blood alcohol concentration curve. Alcohol: Clin Exp Psychol 27: 773-779.

Schreckenberger M, Amberg R, Scheurich A, Lochmann M, Tichy W, Klega A et al (2004). Acute alcohol effects on neuronal and attentional processing: Striatal reward system and inhibitory sensory interactions under acute ethanol challenge. Neuropsychopharmacology 29: 1527-1537.

Schweizer TA, Jolicœur P, Vogel-Sprott M, Dixon MJ (2004). Fast, but error prone responses, during acute alcohol intoxication: Effects of stimulus-response mapping complexity. Alcohol: Clin Exp Res 28: 643-649.
Schweizer TA, Vogel-Sprott M, Dixon MJ, Jolicœur P (2005). The stage-specific effect of alcohol on human information processing. Psychopharmacology 178: 52-57.

Stuss DT, Alexander M (2000). Executive functions and the frontal lobes: a conceptual view. Psychol Res 63: 289-298.

Vogel-Sprott M (1992). Alcohol Tolerance and Social Drinking: Learning the Consequences. Guilford Press: New York.

Vogel-Sprott M, Easdon C, Fillmore M, Finn P, Justus A (2001). Alcohol and behavioral control: cognitive and neural mechanisms. Alcohol: Clin Exp Res 25: 117-121.

Vogel-Sprott M, Fillmore MT (1993). Impairment and recovery under repeated doses of alcohol: Effects of response-outcomes. Pharmacol Biochem Behav 45: 59-63. 